\title{
Histopathological and Histomorphometric Analysis of Pancreas and Liver of Diabetic Rats Treated with Mucuna Pruriens Seed Extract
}

\author{
R Rajesh ${ }^{1}$, Dhananjay Shrikant Kotasthane ${ }^{2 *}$, Manimekalai K ${ }^{3}$, Arunchandra Singh ${ }^{4}$, Sreekala $V^{5}$ and S S Rajasekar ${ }^{1}$ \\ ${ }^{1}$ Department of anatomy, Mahatma Gandhi Medical College and Research Institute, Pondicherry, India \\ ${ }^{2}$ Department of Pathology, Mahatma Gandhi Medical College and Research Institute, Pondicherry, India \\ ${ }^{3}$ Department of Pharmacology, Mahatma Gandhi Medical College and Research Institute, Pondicherry, India \\ ${ }^{4}$ Department of anatomy, Nobel Medical College, Nepal \\ ${ }^{5}$ Dravyaguna Vijnana VPSV Ayurveda College, Kottakkal, Kerala. India
}

\begin{abstract}
Background: Medicinal plants play a major role in controlling diabetes by producing microstructural changes in liver and pancreas. Quantification of islets and hepatocytes by using histomorphometric tools are effective in evaluating the antidiabetic action of drugs.

Aims and Objectives: To assess the anti diabetic properties of alcoholic extracts of Mucuna Pruriens seeds ( $200 \mathrm{mg} / \mathrm{kg}$ b.w) by means of histological and histomorphometric analysis of pancreas and liver.

Methods: Seventy two neonatal wistar rats were randomly divided into four groups, i.e. Normal, Diabetic control, diabetic rats treated with Mucuna and Glibenclamide. Diabetes was induced by a single intraperitoneal administration of streptozotocin ( $65 \mathrm{mg} / \mathrm{kg}$ b.w) in $5 \mathrm{day}$ old neonatal rats $(\mathrm{n}=54) .12$ weeks after the injection, animals were divided in to four groups with 18 animals in each. The study groups were as follows. Group A -Normal control, Group B - STZ untreated, Group C - Mucuna Pruriens 200mg/kg, Group D -Glibenclamide (1mg/kg). Fasting blood sugar levels were monitored once a week during the drug study i.e. 12 weeks. At the end of every 4 th week, 6 animals from each group were sacrificed for histological and histomorphometric studies on liver and Pancreas.

Results: From the histological studies, the diabetic group showed reduction of cell population in the pancreas and depletion of the number of hepatocytes in the liver. After 12 weeks of Drug treatment, These changes were markedly reduced in Mucuna Pruriens treated group. The obtained results were further quantified by means of Histomorphometric analysis and the results showed reduction in the number and diameter of islets, number of beta cells and number of healthy hepatocytes in diabetic control group and treatment with Mucuna Pruriens seed extract significantly reversed these changes $(\mathrm{p}<0.05)$
\end{abstract}

Keywords: Histomorphometric Analysis, Mucuna Pruiens, Pancreas, Liver, Diabetes

\section{Introduction}

Diabetes is on the rise. No longer a disease of predominantly rich nations, the prevalence of diabetes is steadily increasing everywhere, most markedly in the world's middle-income countries. Based on a recent systematic review, it has been estimated that the direct annual cost of diabetes to the world is more than US\$ 827 billion $^{[1]}$. The International Diabetes Federation (IDF) estimates that total global health-care spending on diabetes more than tripled over the period 2003 to 2013 - the result of increases in the number of people with diabetes and increases in per capita diabetes spending ${ }^{[2]}$.

Diabetes mainly affects the metabolic functions of liver and pancreas; primarily beta cells in islets of Langerhans. Streptozotocin is derived from a soil bacterium called Streptomyces Achromogenes, produces permanent damage to the beta cells by DNA fragmentation and oxidative stress, which leads to a reduction in the beta cell mass and pancreatic islets. Furthermore it elicits microstructural damage in hepatocytes, that adversely affects the glucose and lipid metabolism ${ }^{[3]}$.The effectiveness of the antidiabetic agents like biguinaides, sulphonylureas and metformins are mostly dose dependent and prone to side effects ${ }^{[4]}$.

In Indian system of Medicine, many plants are effectively used in diabetes treatment ${ }^{[5]}$.The Mucuna Pruriens Linn. (Fabaceae), generally known as cowhage, is used for the treatment of Erecile Dysfunction and Parkinsonism in Ayurveda. Several research studies have been conducted on the antidiabetic activities of the seeds of MP through biochemical and hematological studies. However, most of this research was short term and no histopathological and histomorphometric parameters were incorporated ${ }^{[6]}$. Hence 
the present study was undertaken to analyze the effects of Mucuna Pruriens seed extract in diabetic wistar rats by histological and histomorphometric analysis.

\section{Materials and Method}

The research protocol has been duly approved by IAEC of Mahatma Gandhi Medical College and Research Institute, SBV University, Puducherry and CPCSEA (686/02/a/ CPCSEA). Five-day old neonate wistar rats (n-72) were received from the Central Animal House of Mahatma Gandhi Medical College and Research Institute. The rats were made diabetic by a single dose i.p. injection of streptozotocin (Sigma Aldrich, U.S.A) (65 mg/kg b.w) dissolved in ice cold citrate buffer (0.1M, pH-4.5). After 4 weeks, blood sugar levels [BGL] were measured by using a one - touch glucometer (Accu Chek, Roche Diagnostics, USA) and animals showing value $>150 \mathrm{mg} / \mathrm{dl}$ of BGL were selected for the drug study ${ }^{[7]}$. The animals were kept under standard laboratory conditions, fed with standard pellet diet and water ad libitum. 12 weeks after the injection, the rats were classified into four groups of eighteen in each. The groups are as follows

Group A - Normal control (Non diabetic rats); Group B Diabetic control; Group C - Experimental drug (Mucuna Pruriens Seed extract 200mg/kg b.w); Group D-Standard drug (Glibenclamide $1 \mathrm{mg} / \mathrm{kg} \mathrm{b.w)}$.

The alcoholic extract of Mucuna Pruriens $(200 \mathrm{mg} / \mathrm{kg}$ body weight) and glibenclamide ( $1 \mathrm{mg} / \mathrm{kg}$ body weight) were administered orally for 12 weeks. The Fasting Blood Glucose Level [FBGL] was measured once a week during the treatment period with the help of a one - touch glucometer (Accu Chek, Roche Diagnostics, USA). After every four weeks of drug treatment, six animals from each group were sacrificed by painless cervical dislocation under mild chloroform anesthesia.

Liver and pancreas were carefully dissected out and transferred to normal saline solution in a petridish. After wiping out the water content with a tissue paper, the organs were weighed by using a digital weighing machine .Then the liver specimens were transferred to $10 \%$ neutral buffer formalin and the pancreas to freshly prepared bouin's fluid. After 48 hours of fixation, the tissues were processed for histological studies. Pancreatic and liver Sections were stained with haematoxylin and eosin (H\&E) and Gomori's chrome alum haematoxylin phloxine stain. The tissue sections were analyzed under a trinocular research microscope (Olympus CX 41) fitted with camera (Olympus E420).

Histomorphometry: Conventional stereological principles and accepted morphometric procedure ${ }^{[8,9]}$ were followed to obtain quantitative information about the pancreatic islets and hepatic parenchyma. 100 serial sections from each group were examined with an ocular micrometer and a calibrated graticule. The parameters analyzed were The number of beta cells per unit area, the diameter of the islets per unit area, the number islets per unit area, the number of healthy and necrotic hepatocytes per unit area and number of binucleated hepatocytes per unit area

The islet area was calculated in each pancreatic section at $400 \mathrm{X}$ magnification with the help of an area calibrated ocular grid. The number of islets and the area of pancreatic tissue were counted at $40 \mathrm{X}$ magnification using the ocular grid. The total number of islets was expressed as N/10 $\mathrm{mm}^{2}$ of the pancreatic parenchyma. The number of beta cells and hepatocytes were determined by direct counting method at 1000X magnification using the ocular grid.

To analyze the diameter of islets, the major axis (a) and minor axis at right angles to the major axis of the islets (b) were measured , and the diameter of the islet (Di) is calculated using the formula (Di) $=\sqrt{ } \mathrm{ab}(10)$ but fall into two basic categories: images of sections through the structure and projection images viewed through it. The most intensive use of stereology has been in conjunction with microscope images, which includes light microscopes (conventional and confocal.

Statistical Analysis: The observed data were subjected to one-way ANOVA and the significance was determined using a "Tukey's post-hoc" with $\mathrm{P}<0.05$ for statistical significance. The statistical tests were performed using software SPSS 15.

\section{Results}

Fasting blood glucose level In the diabetic group, a significant rise in the blood glucose level was noted (P value $<0.05$ ). Treatment with $M P$ seed extract resulted in statistically significant reduction of blood glucose level when compared to diabetic control (Table 1). The oral administration of Mucuna Pruriens produced statistically significant decrease in FBGL $(65.4 \%$ reduction $)(\mathrm{P}<0.01)$.

In the diabetic pancreas, decrease in pancreatic islet's size and number, atrophy and vacoulations, cellular infiltrations, clumping of beta cells and moderate to heavy beta cell destruction were detected. While these abnormal histological signs were significantly decreased as in Mucuna Pruriens treated rats. The inflammatory cells and necrotic changes gradually decreased with mild beta cell clumping and increased number of beta cells in the islets.

The structural changes in the pancreas in the glibenclamide group showed similar changes as observed in mucuna group. 
In the liver, hydropic dystrophy necroses of hepatocytes and lymphatic infiltration were observed in diabetic rats. In addition to this, dilated sinusoidal space and damaged periportal areas were also visible. Whereas, regenerative changes were observed with the Mucuna Pruriens group. i.e, increased number of binucleated hepatocytes, reduced necrotic cells and lymphatic infiltrations.

The results of the histomorphometric assessmentshows that total Number of pancreatic islets was markedly decreased in diabetic control group when compared to the control group (Table no 2.). Whereas a significant increase was observed with Mucuna Pruriens and glibenclamide group $(\mathrm{P}<0.05)$. The diameter is significantly reduced in the diabetic control group and the shape of the islets was altered (Table. 3). Treatment with Mucuna Pruriens resulted in the partial recuperation of the shape and the diameter $(\mathrm{P}$
$<0.05)$. Streptozotocin primarily targets beta cells of the islets, which comprises $75 \%$ of islet population. The beta cell population was drastically decreased in diabetic group when compared to the Normal control group (table no -4). The Mucuna Pruriens treatment resulted in increased number of beta cells in the islet. The obtained data was statistically significant by $12^{\text {th }}$ week $(\mathrm{P}<0.05)$.

In diabetic control, the number of hepatocytes was significantly decreased, and the number of necrotic cells was increased (Table. 5). In Mucuna Pruriens treated group, a statistically significant decrease in the necrotic cells and in increase in the number of healthy hepatocytes were noted. Towards the end the drug study the number of active hepatocytes and binucleated hepatocytes were markedly improved in the Mucuna Pruriens group when compared to diabetic. $\mathrm{P}<0.05$.

Table 1: The effect ofMucuna Pruriens seed extract on Fasting Blood glucose level (in mg/dL).

\begin{tabular}{|c|c|c|c|c|}
\hline Period (weeks) & Control & Diabetic & Mucuna & Glibenclamide \\
\hline $1^{\text {st }}$ & $83.1 \pm 2.3$ & $186 \pm 2.9^{*}$ & $179 \pm 2.76^{*}$ & $175 \pm 3.12^{*}$ \\
\hline $2^{\text {nd }}$ & $83.4 \pm 2.1$ & $187.9 \pm 2.99^{*}$ & $172 \pm 2.65^{*}$ & $169.2 \pm 2.93^{*}$ \\
\hline $3^{\text {td }}$ & $82.9 \pm 2.3$ & $190 \pm 2.95^{*}$ & $168.6 \pm 2.65^{*}$ & $160.1 \pm 2.54^{*}$ \\
\hline $4^{\text {th }}$ & $83.5 \pm 2.2$ & $195 \pm 3.53^{*}$ & $163.6 \pm 2.33^{*}$ & $156.8 \pm 2.98^{*}$ \\
\hline $5^{\text {th }}$ & $84.6 \pm 2.4$ & $201.5 \pm 3.62^{*}$ & $158.2 \pm 2.43^{*}$ & $152 \pm 2.94^{*}$ \\
\hline $6^{\text {th }}$ & $85.1 \pm 2.2$ & $206.2 \pm 4.02^{*}$ & $154.4 \pm 2.78^{*}$ & $150.2 \pm 2.87^{*}$ \\
\hline $7^{\text {th }}$ & $83.2 \pm 2.6$ & $208.2 \pm 3.59^{*}$ & $150.6 \pm 2.54^{*}$ & $148.4 \pm 2.87^{*}$ \\
\hline $8^{\text {th }}$ & $84.2 \pm 2.3$ & $210.3 \pm 3.92^{*}$ & $146.5 \pm 2.22^{*}$ & $147.1 \pm 2.80^{*}$ \\
\hline $9^{\text {th }}$ & $83.6 \pm 2.3$ & $211.1 \pm 4.45^{*}$ & $143.3 \pm 2.11^{*}$ & $146.6 \pm 2.44^{*}$ \\
\hline $10^{\text {th }}$ & $82.1 \pm 2.6$ & $211.4 \pm 4.52^{*}$ & $140.3 \pm 2.32^{*}$ & $145 \pm 2.55^{*}$ \\
\hline $11^{\text {th }}$ & $81.2 \pm 2.7$ & $210 \pm 4.22^{*}$ & $134.4 \pm 2.98^{*}$ & $143.5 \pm 2.65^{*}$ \\
\hline $12^{\text {th }}$ & $83.1 \pm 2.1$ & $209.5 \pm 4.3^{*}$ & $126.8 \pm 2.99^{*}$ & $142.5 \pm 2.71^{*}$ \\
\hline
\end{tabular}

Mean $\pm S D, *=P<0.05$. Normal compared with diabetic, and diabetic compared with MP and GC

Table 2: The number of islets per unit area of pancreas[N/10 $\left.\mathrm{mm}^{2}\right]$.

\begin{tabular}{|c|c|c|c|}
\hline Group & $4^{\text {th }}$ week & $\mathbf{8}^{\text {th }}$ week & $12^{\text {th }}$ week \\
\hline Control & $15 \pm 3.01$ & $14 \pm 3.23$ & $14 \pm 3.32$ \\
\hline Diabetic & $5 \pm 1.34^{*}$ & $4 \pm 1.54^{*}$ & $4 \pm 1.43^{*}$ \\
\hline MP extract & $8 \pm 2.74^{*}$ & $10 \pm 3.45^{*}$ & $11 \pm 2.26^{*}$ \\
\hline Glibenclamide & $8 \pm 2.43$ & $9 \pm 2.45$ & $10 \pm 2.12$ \\
\hline
\end{tabular}

Mean $\pm S D, *=P<0.05$, Normal control compared with diabetic, and diabetic compared with MP and GC.

Table 3: The Mean diameter of islets $[\mu \mathrm{m}]$.

\begin{tabular}{|c|c|c|c|}
\hline Group & $4^{\text {th }}$ week & $8^{\text {th }}$ week & $12^{\text {th }}$ week \\
\hline Control & $132.4 \pm 14.32$ & $130 \pm 14.8$ & $129 \pm 12.3$ \\
\hline Diabetic & $61.3 \pm 72^{*}$ & $59 \pm 6.44$ & $59 \pm 6.33$ \\
\hline Mucuna & $92.3 \pm 9.26^{*}$ & $95.9 \pm 9.87^{*}$ & $97.7 \pm 6.64^{*}$ \\
\hline Glibenclamide & $96.1 \pm 8.46^{*}$ & $95 \pm 5.58^{*}$ & $96.1 \pm 5.13^{*}$ \\
\hline
\end{tabular}

Mean $\pm S D, *=P<0.05$, Normal compared with diabetic, and diabetic compared with MP and GC. 
Table 4: Number of beta cells per unit area of Islets[N/1000 $\left.\mu^{2}\right]$.

\begin{tabular}{|c|c|c|c|}
\hline Group & $4^{\text {th }}$ week & $8^{\text {th }}$ week & $12^{\text {th }}$ week \\
\hline Control & $11 \pm 2.34$ & $12 \pm 3.3$ & $11 \pm 3.32$ \\
\hline Diabetic & $4 \pm 1.12^{*}$ & $3 \pm 1^{*}$ & $3 \pm 1.34^{*}$ \\
\hline Mucuna & $6 \pm 2.23$ * & $7 \pm 2^{*}$ & $8 \pm 2.45^{*}$ \\
\hline Glibenclamide & $6 \pm 2.13$ & $6 \pm 2^{*}$ & $7 \pm 3.34^{*}$ \\
\hline
\end{tabular}

Mean $\pm S D, *=P<0.05$, Normal compared with diabetic, and diabetic compared with MP and GC.

Table 5. Histomorphometric analysis of the liver [N/1000 $\mu \mathrm{m} 2]$.

\begin{tabular}{|c|c|c|c|c|}
\hline Parameter & Group & $4^{\text {th }}$ week & $8^{\text {th }}$ week & $12^{\text {th }}$ week \\
\hline \multirow{4}{*}{ Number of normal hepatocytes } & Control & $21 \pm 03.21$ & $22 \pm 3.31$ & $20 \pm 3.32$ \\
\hline & Diabetic & $6 \pm 2.32^{*}$ & $6 \pm 3.15^{*}$ & $7 \pm 3.43^{*}$ \\
\hline & Mucuna & $10 \pm .13^{*}$ & $12 \pm 4.22^{*}$ & $15 \pm 3.21^{*}$ \\
\hline & Glibenclamide & $9 \pm 2.14^{*}$ & $12 \pm 3.64^{*}$ & $13 \pm 2.32^{*}$ \\
\hline \multirow{4}{*}{ Number of necrotic hepatocytes } & Control & $1 \pm 1.87$ & $2 \pm 1.62^{*}$ & $1 \pm 1.37^{*}$ \\
\hline & Diabetic & $18 \pm 2.24^{*}$ & $17 \pm 3.83^{*}$ & $17 \pm 1.75^{*}$ \\
\hline & Mucuna & $10 \pm 3.11^{*}$ & $09 \pm 4.42^{*}$ & $6 \pm 03.32^{*}$ \\
\hline & Glibenclamide & $9 \pm 3.04^{*}$ & $10 \pm 3.12^{*}$ & $11 \pm 03.2^{*}$ \\
\hline \multirow{4}{*}{$\begin{array}{l}\text { Number of binucleated } \\
\text { hepatocytes }\end{array}$} & Control & $3 \pm 1.5$ & $3 \pm 1.54$ & $3 \pm 1.2^{*}$ \\
\hline & Diabetic & $2 \pm 1.54^{*}$ & $2 \pm 1.34^{*}$ & $2 \pm 1.43^{*}$ \\
\hline & Mucuna & $5 \pm 3.5^{*}$ & $6 \pm 3.65^{*}$ & $6 \pm 3.43^{*}$ \\
\hline & Glibenclamide & $6 \pm 3.9$ & $4 \pm 3.9^{*}$ & $3 \pm 3.43^{*}$ \\
\hline
\end{tabular}

Mean $\pm S D, *=P<0.05$, Normal compared with diabetic, and diabetic compared with MP

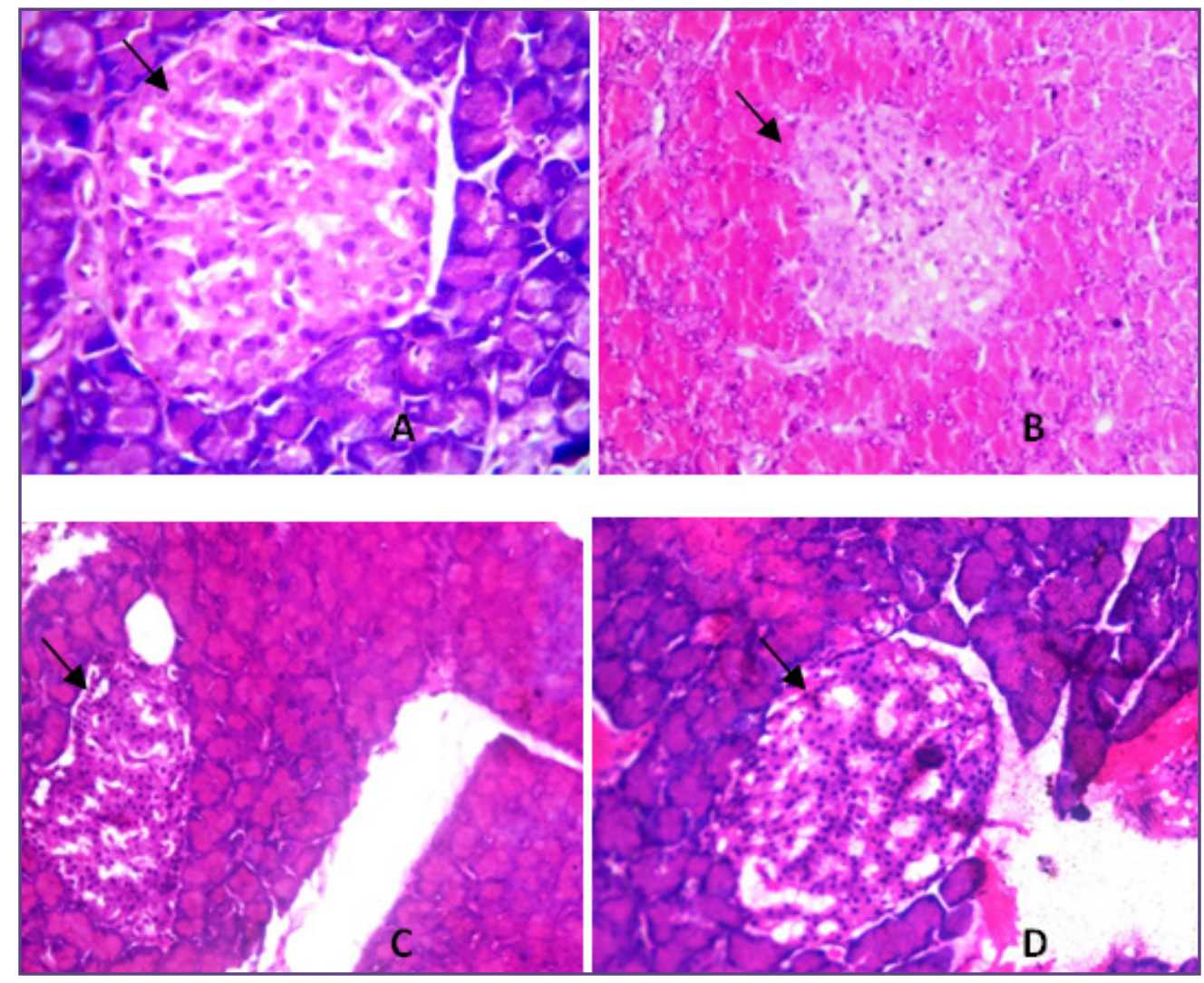

Fig. 1: Pancreas 12th week - H\&E Staining : 400x magnification A - Normal islets showing plates of beta cells with sinusoidal spaces. B. Diabetic pancreas showing severe destruction of islets with necrotic beta cells .C \& D. Mucuna pruriens and Glibenclamide group showing active regeneration of beta cells. 


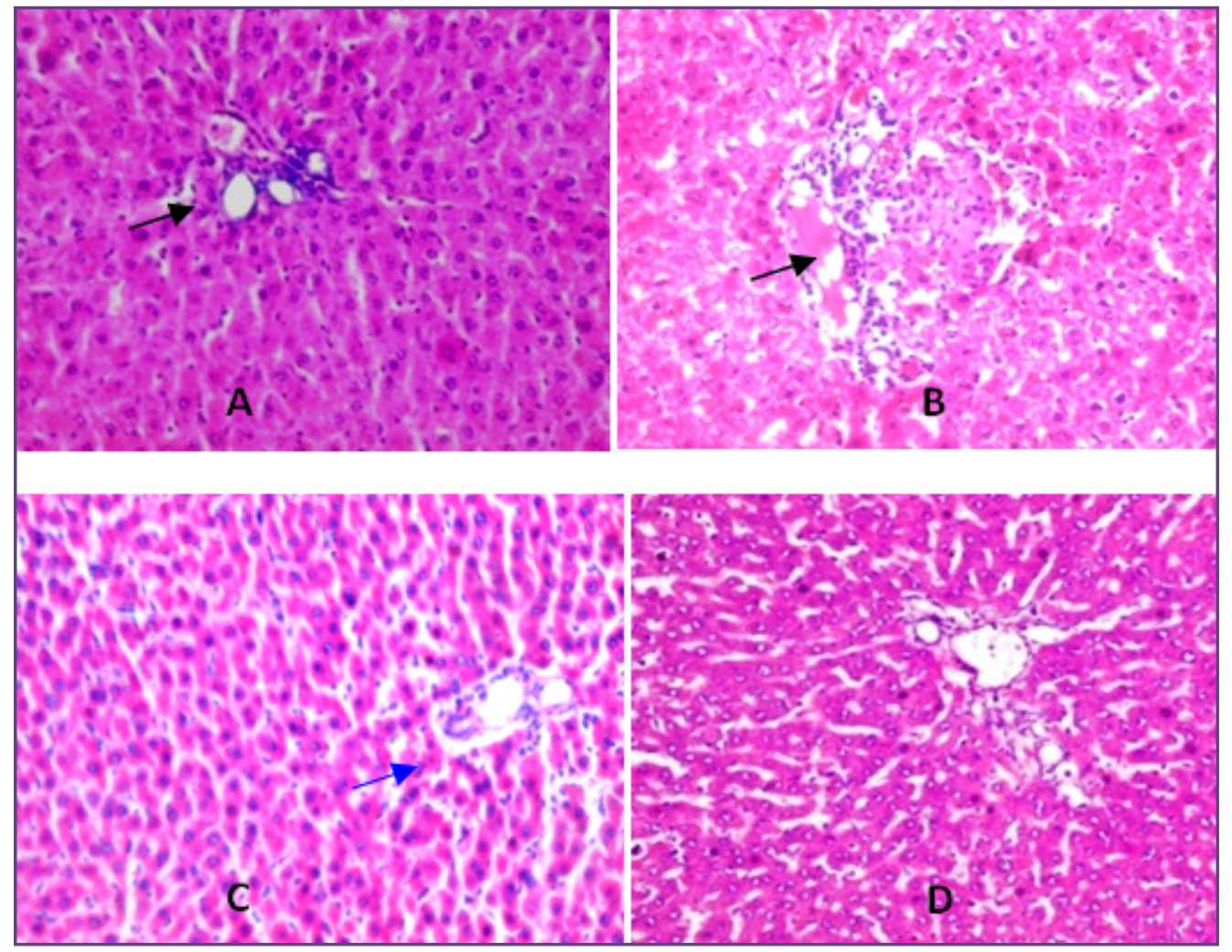

Fig. 2: Liver - 12th week - H\&E Staining : 400x magnification A - Normal liver showing portal area and normal hepatocytes with sinusoidal space. B - Diabetic control Liver showing rigorous damage to the portal area with necrotic hepatocytes and infiltrations. C - Mucuna pruriens group showing near normal portal area with few binucleated hepatocytes. D Glibenclamide group showing chords of hepatocytes with minimal necrosis of hepatocytes.

\section{Discussion}

Diabetes mellitus comprises a group of heterogeneous disorders which affects almost all systems of the body. Apart from the currently available drugs for the treatment of diabetes, a wide spectrum of drugs extracted from plant species were studied for their anti-diabetic properties. On these backgrounds, the present study was designed to evaluate the antidiabetic properties of Mucuna Pruriens seed extract on the structural changes liver and pancreas of Streptozotocin-induced Type 2 diabetic rats by quantitative and qualitative methods.

Chemical induction of diabetes by injection of a single dose of streptozotocin is a widely accepted model for diabetic experimental studies in rodents ${ }^{[10]}$ consequences and treatment of diabetes. There are different ways to induce experimental diabetes, chemically induced experimental diabetes has been widely used. Alloxan and streptozotocin are the chemicals most used. A comparative study of these two agents was performed in order to determine their effectiveness. Twenty-seven Sprague-Dawley male adult rats were intraperitoneally (i.p.] .High doses of STZ injection in adult rats produces typel diabetes, whereas injection of STZ at the neonatal period produces features more or less similar to type 2 diabetes in adult rats. ${ }^{[11]}$ In the present study, 5-day old neonate wistar rats were made diabetic by $65 \mathrm{mg} / \mathrm{kg}$ body weight of STZ. The drug study started after twelve weeks after injection ie, once the animals reaches adult period.

Results of this study shows that the oral treatment of Mucuna Pruriensproduced a significant 65\% reduction of blood glucose level after 12 weeks of drug treatment $(p<0.05)$. previous researchers like, Anusha et al reported that 21 days oral treatment of water extract of Mucuna Pruriens $200 \mathrm{mg} / \mathrm{kg}$ b.w is capable of reducing hyperglycemia by $40.7 \%^{[12]}$. These variations may be attributed to the climatic conditions, the maturity of the plant and soil composition, which leads to significant changes the pharmacological properties of herbs and actual dose of active ingredients ${ }^{[13]}$ Mucuna spp. (Fabaceae).

Streptozotocin (STZ) is a naturally occurring compound, produced by the bacterium Streptomyces achromogenes, that produces diabetes in rodents through severe oxidative stress by free radical formation and through inhibition of DNA synthesis. It involves partial to complete destruction 
of the islets and reduction of the diameter of islets, vacuolation and necrosis of the beta cells ${ }^{[14,15]}$. In liver, STZ damages the hepatic parenchyma leading to vacuolations and necrosis of hepatocytes, dilation of sinusoidal spaces, periportal inflammation, congestion and hemorrhage ${ }^{[16,17]}$ etc.All these changes were evident in the diabetic control group. The oral treatment of Mucuna Pruriens seed extract resulted in regeneration of beta cells of the islets, and increase in the number of hepatocytes in the liver. Anusha et al suggested that the dietary fibers and essential minerals present in the Mucuna Pruriens exerting the hypoglycemic effects $^{[12]}$. It has been suggested that bioactive phytochemical compounds, having antihyperglycaemic activities, might act through several mechanisms such as stimulating insulin secretion, increasing repair, or proliferation of beta cells and enhancing the effects of insulin.

The reduction in the number of beta cells, size and number of islets in the diabetic group may be attributed to the direct cytotoxic effects of streptozotocin on the beta cells of the islets. Statistically significant increase $(p<0.05)$ in the number and diameter of islets were observed with MP group. This indicates that mucuna Pruriens produced regeneration of beta cells and islets. The regeneration of the STZ-destructed islets is probably due to the fact that the ductal epithelium of the pancreas, from which the pancreatic islets of Langerhans develops, presents dormant stem cells possess the ability of regeneration, replace the lost cells by transforming the surviving cells to proliferate into active cells under favorable conditions[18].

Polyploidation of hepatocytes is believedas an original physiological mechanism in which the cells pass through a binucleation stage which helps them to elevate metabolic yield and constitutes a substitute to cell division ${ }^{[19]}$. The outcome of the histomorphometric analysis of liver is supporting the suggestions put forwarded by the previous researchers. The reduction of necrotic cells, increased healthy hepatocytes and increased binucleated cells per unit area may be the indications of dynamic metabolic activity of hepatocytes due to the ameliorative effects of Mucuna on liver ${ }^{[20,21]}$. Circulating free radicals are suggested as the mechanism of heaptotoxicity in STZ-induced diabetes. Presence of antioxidant bioactive components might be protecting the hepatocytes from the free radicals.

\section{Conclusion}

Results suggests that the alcoholic extract of the test drug is effective against the degenerative changes in the liver and pancreas in the diabetic rats. Further histomorphometric analysison the hepatocytes and pancreatic beta cells were in concordance with the histological and hematological findings. It is concluded that Mucuna Pruriens seed has favorable effect to protect from the hyperglycemia and the microstructural changes in liver and pancreas by STZ induced diabetes.

\section{References}

1. Worldwide trends in diabetes since 1980: a pooled analysis of 751 population-based studies with $4 \cdot 4$ million participants. Lancet. 2016 Apr;387(10027):1513-30.

2. Gao HX, Regier EE, Close KL. International Diabetes Federation World Diabetes Congress 2015. J Diabetes. 2016 May ;8(3):300-2.

3. Ogbonnaya EC, Eleazu KC, Chukwuma S, Essien UN. Review of the mechanism of cell death resulting from streptozotocin challenge in experimental animals, its practical use and potential risk to humans. J Diabetes Metab Disord . 2013;12(1):60.

4. Stern Z, Levy R. Analysis of direct cost of standard compared with intensive insulin treatment of insulin dependent diabetes mellitus and cost of complications. Acta Diabetol. 1996;33(1):48-52.

5. Elder C. Ayurveda for diabetes mellitus: A review of the biomedical literature. Altern Ther Health Med. 2004;10(1):44-50.

6. Majekodunmi SO, Oyagbemi AA, Umukoro S, Odeku OA. Evaluation of the anti-diabetic properties of Mucuna pruriens seed extract. Asian Pac J Trop Med. 2011;4(8):632-6.

7. Akbarzadeh A, Norouzian D, Mehrabi MR, Jamshidi S, Farhangi A, Allah Verdi A, et al. Induction of diabetes by Streptozotocin in rats. Indian $\mathrm{J}$ Clin Biochem. 2007;22(2):60-4.

8. Portha B, Blondel O, Serradas P, McEvoy R, Giroix MH, Kergoat M, et al. The rat models of non-insulin dependent diabetes induced by neonatal streptozotocin .Diabète \& métabolisme 1989;15(2):61-75.

9. West MJ. Introduction to stereology. Cold Spring Harb Protoc. 2012;7(8):843-51.

10. Elias H, Hyde DM. An elementary introduction to stereology (quantitative microscopy). Am J Anat. 1980;159(4):411-46.

11. Dorothy IS and WR. Animal Models in Diabetes Research. Anim Model Diabetes Res. 2012;933:219-28.

12. Srinivasan K, Ramarao P. Animal models in type 2 diabetes research: an overview. Indian J Med Res. 2007;125(3):451-72.

13. Bhaskar A, Vidhya VG, Ramya M. Hypoglycemic effect of Mucuna pruriens seed extract on normal and streptozotocindiabetic rats. Fitoterapia. 2008;79(7-8):539-43.

14. Lorenzetti F, Macisaac S, Arnason JT, Buckles D. The phytochemistry, toxicology, and food potential of velvetbean (Mucuna Adans. spp., Fabaceae). Africa (Lond). 2010;1-11.

15. Tatar M, Qujeq D, Feizi F, Parsian H, Sohan Faraji A, Halalkhor S, et al. Effects of Teucrium Polium Aerial Parts extract on oral glucose tolerance tests and pancreas 
histopathology in Streptozocin-induced diabetic rats. Int J Mol Cell Med [Internet]. 2012;1(1):44-9.

16. Nugent DA, Smith DM, Jones HB. A review of islet of Langerhans degeneration in rodent models of type 2 diabetes. Toxicol Pathol. 2008;36(4):529-51.

17. Herrman CE, Sanders RA, Klaunig JE, Schwarz LR, Watkins JB. Decreased apoptosis as a mechanism for hepatomegaly in streptozotocin- induced diabetic rats. Toxicol Sci. 1999;50(1):146-51.

18. Rajesh R, Singh AS, Vaithy AK, Manimekalai K, Kotasthane D, Rajasekar SS. The effect of mucuna pruriens seed extract on pancreas and liver of diabetic wistar rats. Int J Cur Res Rev. 2016;8(4).
19. Bhartiya D. Stem cells to replace or regenerate the diabetic pancreas: Huge potential \&amp; existing hurdles. Indian J Med Res. 2016;143(3):267-74.

20. Celton-Morizur S, Merlen G, Couton D, Desdouets C. Polyploidy and liver proliferation Central role of insulin signaling. Vol. 9, Cell Cycle. 2010. p. 460-6.

21. Lee E, Kwack SJ, Park KL, Kim SH, Kang TS, Lee J, et al. Evaluation of liver and thyroid toxicity in Sprague-Dawley rats after exposure to polybrominated diphenyl ether BDE209. J Toxicol Sci. 2010;35(4):535-45.

22. Zaret KS, Grompe M. Generation and regeneration of cells of the liver and pancreas. Science. 2008;322(5907):1490-4.

*Corresponding author:

Dr. Dhananjay S Kotasthane, Professor and HOD, Mahatma Gandhi Medical College and Research Institute, Pillaiyarkuppam, Pondicherry, India

Phone: +91 9092096244

Email: dskotasthane@gmail.com

Date of Submission : 19.05.2017

Date of Acceptance : 10.06.2017

Financial or other Competing Interests: None.

Date of Publication : 26.10.2017 